\title{
Central poststroke pain: An abstruse outcome
}

\author{
James L Henry PhD, Chitra Lalloo BHSc, Kiran Yashpal PhD
}

\author{
JL Henry, C Lalloo, K Yashpal. Central poststroke pain: An \\ abstruse outcome. Pain Res Manage 2008;13(1):41-49.
}

Central poststroke pain (CPSP), formerly known as thalamic pain syndrome of Déjerine and Roussy, is a central neuropathic pain occurring in patients affected by stroke. It is one manifestation of central pain, which is broadly defined as central neuropathic pain caused by lesions or dysfunction in the central nervous system. Thalamic pain was first described 100 years ago by Déjerine and Roussy and has been described as "among the most spectacular, distressing, and intractable of pain syndromes". CPSP is characterized by constant or intermittent pain and is associated with sensory abnormalities, particularly of thermal sensation. While the pain is frequently described as burning, scalding, or burning and freezing, other symptoms are usually vague and hard to characterize, making an early diagnosis particularly difficult. In fact, those who develop CPSP may no longer be under the care of health care professionals when their symptoms begin to manifest, resulting in misdiagnosis or a significant delay before treatment begins. Diagnosis is further complicated by cognitive and speech limitations that may occur following stroke, as well as by depression, anxiety and sleep disturbances. Patients may also exhibit spontaneous dysesthesia and the stimulus-evoked sensory disturbances of dysesthesia, allodynia and hyperalgesia. The present study offers a historical reference point for future clinical and basic research into this elusive type of debilitating pain.

Key Words: Allodynia; Central neuropathic pain; Hypersensitivity; Poststroke pain; Stroke; Thalamic syndrome

$\mathrm{T}$ he decision to compile a literature review on the subject of central poststroke pain (CPSP) may understandably generate some skepticism. After all, this syndrome, however intrinsically interesting, has not been a major focus of the research community. Indeed, most of the relatively few studies of treatment that have been published cannot claim the gold standard of the randomized, controlled trial. Why, then, do we think it necessary to capture the current state of CPSP as of 2008?

First, this disease affects an estimated $8 \%$ of all stroke patients, and possibly more (1). Even this minimum value represents a significant population that is worthy of study. For instance, of the 700,000 new and recurrent cases of stroke in the United States each year, we can expect at least 56,000 cases of CPSP (2). Second, this pain is largely refractory to medical and surgical treatment and thereby constitutes an

\section{La douleur centrale après un AVC : Une issue abstruse}

La douleur centrale après un accident vasculaire cérébral (DCA), qu'on appelait auparavant «syndrome thalamique de Déjerine et Roussy », est une douleur névropathique centrale ressentie par des patients souffrant d'un AVC. C'est une manifestation de douleur centrale, largement définie par une douleur névropathique centrale causée par des lésions ou un dysfonctionnement du système nerveux central. Déjerine et Roussy ont défini la douleur thalamique pour la première fois il y a cent ans et l'ont décrite comme l'un des syndromes de douleur les plus spectaculaires, les plus pénibles et les plus réfractaires. La DCA se caractérise par une douleur constante ou intermittente et s'associe à des anomalies sensorielles, notamment la sensation thermique. La douleur est souvent décrite comme une sensation de brûlure, d'ébouillantage ou de brûlure et de gel. D'autres symptômes sont généralement vagues et difficiles à caractériser, ce qui complique particulièrement le diagnostic précoce. En fait, les personnes qui développent une DCA ne sont peut-être plus suivies par un professionnel de la santé lorsque leurs symptômes se manifestent, ce qui entraîne un mauvais diagnostic ou un retard important avant le début du traitement. De plus, le diagnostic est compliqué par les limites cognitives et de la parole possibles après un AVC, ainsi que par la dépression, l'anxiété et les troubles du sommeil. Les patients peuvent également présenter une dysesthésie active et les troubles sensoriels évoqués par des stimuli causés par la dysesthésie, l'allodynie et l'hyperalgésie. La présente étude offre un point de référence historique pour les futures recherches cliniques et fondamentales sur ce type de douleur débilitante fugace.

Michael G DeGroote Institute for Pain Research and Care, McMaster University, Hamilton, Ontario

Correspondence: Dr James L Henry, Michael G DeGroote Institute for Pain Research and Care, McMaster University, 1200 Main Street West,

HSC 1J11, Hamilton, Ontario L8N 325. Telephone 905-525-9140 ext 27704, fax 905-522-8844, e-mail jhenry@mcmaster.ca 
first documentation of CPSP (4). While this conference established research guidelines for future projects, it also highlighted the absence of a comprehensive, definitive source of information on the state of the art. Furthermore, the recently proposed challenge to create an animal model of CPSP necessitates a thorough examination of this disorder; it must be clear what is to be modelled. Within this perspective, the present review aims to delineate the changes in historical perspective on central pain in general as well as to provide a brief survey of what is CPSP.

\section{APOPLEXY TO STROKE}

Over 2400 years ago, Hippocrates observed an alarmingly sudden onset of dizziness and paralysis in certain patients. He described this unusual phenomenon as 'apoplexy', derived from the Greek apoplessein, meaning 'struck down by the Gods' (5). Following the Hippocratic humoral tradition, apoplexy was attributed to an accumulation of black bile in the brain. At that time, apoplexy was a generalized term that could be applied to any pathology involving sudden paralysis (5). Toward the close of the $18^{\text {th }}$ century, however, the increasing use of postmortem dissection led to a correlation between apoplexy and overall weakening of the arterial vasculature (6). This enhanced anatomical awareness likely contributed to the gradual displacement of 'apoplexy' with the more specific 'cerebrovascular disease'. It has been suggested that this change in orientation also corresponds with a palpable shift away from patient-centred care to a more clinical, diseasebased approach (6). By the mid-1950s, physicians were beginning to acknowledge the benefits of rehabilitation in relation to cerebrovascular disease. The re-emergence of such patientfocused treatment has been temporally linked with the increased popularity of 'stroke illness' to describe Hippocrates' original observations (6).

Stroke is presently defined as an acute loss of neurological function due to interruption of blood to the nervous system or leakage of blood outside of the vessel walls (7). Approximately $85 \%$ of strokes are ischemic in nature, meaning they are caused by reduced blood flow to the nervous system, such as when vessels are blocked by a clot or become too narrow for blood to pass. Hemorrhagic strokes, accounting for the remaining 15\% of cases, occur when blood vessels become damaged or ruptured, and lead to uncontrolled bleeding into the nervous system (7).

According to the American Heart Association (2), stroke incidence approximates 700,000 new cases per year, of which 500,000 are first instances and the remaining 200,000 are recurrent cases. Maximal damage tends to occur within the first $30 \mathrm{~min}$, although additional neurological decline may also take place (8). In cases of ischemic stroke, rapid administration (within $3 \mathrm{~h}$ ) of the thrombolytic agent tissue plasminogen activator (tPA) can prevent permanent damage in selected patients (9). Clinical manifestations of stroke may include sensory loss or impairment, hemiplegia (paralysis in one vertical half of the body), hemiparesis (partial paralysis over one-half of the body), visual defects, dysarthria (slurred speech) and aphasia (disturbed speech), among many others (4).

The clinical features of a stroke are largely dependent upon the specific cerebral regions affected. For instance, stroke in a dimensionally small but functionally eloquent region, such as Wernicke's area, would tend to precipitate more severe symptoms than stroke in other areas, such as the frontal lobe. It has been noted, moreover, that the location of the lesion has greater importance than its absolute size when predicting symptomatic severity (10).

\section{THALAMIC STROKE TO THALAMIC SYNDROME}

Perhaps the place to link the locus of thalamic stroke with sensory dysfunction is in the original reports. The following passage outlines pertinent features of the first case of 'thalamic syndrome', as described by Déjerine and Egger in 1903 (11); English translation by Langworthy and Fox (12):

"Madame Jossaume, a 76-year-old French woman, suffered a stroke in 1902 resulting in total paralysis of her left extremities. Pinprick examination elicited creeping, crawling sensations over the left side (dysesthesia), with no localized awareness of the pain.

"Fifteen days later, the paralysis had receded to be replaced by severe and unrelenting pain over the entire left side. This pain was described as 'burning and crawling', particularly over the left temple, ear, nostril, and tongue.

"Three months later, Madame Jossaume was taken to see Jules Déjerine, a well-known Parisian neurologist. Déjerine's thorough examination revealed a complete absence of touch sensibility in the left hand and forearm, hypoesthesia (decreased sensitivity to stimulation) of the left arm, and mirrored signs in the left foot and thigh. The left side of her face was similarly insensible to touch, while the mucous membranes of the left mouth, palate, pharynx, tongue, cornea and conjunctiva all demonstrated hypoesthesia. Another pinprick test showed renewal of localized pain awareness, which was notably less sharp on the affected side. Further examination demonstrated a heightened sensitivity to heat on the trunk and face, compared to the extremities. Furthermore, the left side of her face was hypoesthetic to heat, but hyperesthetic to cold. Sensibility to applied pressure progressively diminished from the proximal arm to distal phalanges. A vibrating tuning fork placed on the bony prominences of the left side created uncomfortable burning sensations. Remarkably, the patient displayed a complete absence of proprioception (awareness of body position) in her left arm. A similar, albeit less severe phenomenon was observed in the leg. Complete astereognosis (loss of the ability to understand the form and nature of objects by touch) of the left hand was also present.

"On a more positive note, the patient did retain motor function in her extremities and exhibited no loss of muscle tone. Considerable muscle weakness in the left arm and leg, as well as slight paralysis of the left mouth were displayed, however.

"Certain reflexes, namely those of the ankle and patellar tendons, were markedly exaggerated on both sides though particularly so on the left. Conversely, the deep reflexes of the arm were equal on both sides. The patient also presented with a choreic tremor in the left arm, which was influenced by her attention or distraction."

During a meeting of the Paris Neurological Society in April of 1903, Déjerine presented the cases of Madame Jossaume and another patient who exhibited similar symptoms (12). His 
diagnosis of these puzzling cases was a lesion of the optic thalamus (presently known as the lateral geniculate body). In 1904, Thomas and Chiray reported two more cases of almost identical description to those of Déjerine (12).

Madame Jossaume subsequently died and an autopsy was performed in 1905. Noteworthy findings included an enlarged right pyramid and a brown-yellow area in the posterolateral region of the right thalamus (12).

In 1906, Déjerine and the pathologist Gustave Roussy sought to formally describe the manifestations of this new and compelling illness. Cases of centrally arising pain had been described years earlier by Edinger in 1891 (13), Mann in 1892 (14), Weir Mitchell in 1897 (15) and others; however, Déjerine and Roussy provided the first comprehensive description of the phenomenon they termed 'thalamic syndrome'.

The following passage appears in "Le syndrome thalamique" (1906), the seminal paper of Déjerine and Roussy (16); English translation by Wilkins and Brody (17).

"The term thalamic syndrome, as it appears from our personal observations must now be understood as a syndrome characterized by:

1. A slight hemiplegia, usually without contractures.

2. A persistent superficial hemianesthesia of an organic character, which can in some cases be replaced by cutaneous hyperesthesia, but is always accompanied by marked and persistent disturbances of deep sensation.

3. Mild hemiataxia [failure of muscular coordination affecting one half of the body] and more or less complete astereognosis.

"To these three principal and constant symptoms are ordinarily added:

4. Severe, persistent, paroxysmal, often intolerable, pains on the hemiplegic side, not yielding to any analgesic treatment.

5. Choreoathetoid movements in the limbs on the paralyzed side."

In 1907, Roussy analyzed cerebral sections taken from five patients, including Madame Jossaume (12). Along with his experimentation on the effects of artificial thalamic lesions, these pathological specimens helped Roussy to correlate reported clinical symptoms with specific lesions to the optic thalamus.

Following the release of Roussy's La couche optique in 1907, the prominent British neurologist Henry Head published his own observations relating to thalamic syndrome (18; see also interpretations in 12). Head suggested that the destruction of specific thalamic regions could manifest clinically as an overreaction to unpleasant stimuli. He found that stimuli such as pinprick, painful pressure and extreme temperatures all produce heightened distress on the affected side, and further postulated that this phenomenon of overreaction is an essential feature of thalamic syndrome.

\section{THALAMIC SYNDROME TO CENTRAL POSTSTROKE PAIN}

For a variety of reasons, the terminology surrounding thalamic syndrome has been marred with confusion since its characterization in 1906. For example, the term 'central pain' was unknown at the time of Déjerine and Roussy's experimentation, although it forms a cornerstone of their thalamic syndrome. Indeed, 'central pain' was not introduced until 1914 (19) and not formally defined until 1938 when George Riddoch advanced the following description: "spontaneous pain and painful overreaction to objective stimulation resulting from lesions confined to the substance of the central nervous system including dysaesthesia of a disagreeable kind" (20). It is noteworthy that Riddoch's definition speaks not of stroke, but of lesions. Nevertheless, during the years that followed, 'central pain' gradually became synonymous with the painrelated branch of its most famous manifestation, thalamic syndrome. Perhaps this misconception can be attributed to the fact that early central pain pioneers such as Greiff (21) and Edinger (13) dealt almost exclusively with thalamic dysfunction. Today, it is recognized that the $\mathrm{NeP}$ associated with thalamic syndrome is only one example of central pain. Other examples include multiple sclerosis, spinal cord injuries, traumatic brain injuries, syringomyelia and other neurological disorders.

Furthermore, it has been established that central NeP may develop following stroke lesions located ubiquitously along the spinothalamocortical tract (22), not exclusively those restricted to the thalamus. The term 'thalamic syndrome' has thus become a misnomer, because it is not exclusively thalamic damage that may precipitate the same constellation of symptoms (5). Therefore, just as thalamic syndrome cannot be considered synonymous with all central pain, it is also not synonymous with all poststroke pain and more accurately represents one possible manifestation. Nomenclature was improved during the mid-1950s with the introduction of 'CPSP' to describe a central NeP occurring in patients affected by stroke along the somatosensory tract (23). For a visual representation of the journey from thalamic syndrome to CPSP, see Figure 1.

\section{WHAT IS CPSP?}

CPSP is a central neuropathic disorder characterized by constant or intermittent pain. It is associated with sensory abnormalities, particularly of thermal sensation, in the painful body part $(24,25)$. While the pain is frequently described as burning, scalding, or burning and freezing (25), other symptoms are usually vague and hard to characterize, making an early diagnosis particularly difficult (26). In fact, neurologists and other health care professionals may no longer be caring for stroke patients when symptoms of CPSP begin to appear, resulting in frequent misdiagnoses and/or significant delays before treatment begins (26). Diagnosis is further complicated by cognitive and speech problems that occur as a result of stroke, as well as other functional disturbances, including depression, anxiety and sleep disturbances, which are comorbid conditions associated with CPSP. Most patients also experience spontaneous dysesthesia and the stimulus-evoked sensory disturbances of dysesthesia, allodynia and hyperalgesia $(10,24)$.

\section{SOMATOSENSORY ABNORMALITIES FOLLOWING STROKE}

The presence of somatosensory abnormalities is a well-recognized complication of stroke. In a prospective study involving 207 stroke patients, Anderson et al (24) observed 87 subjects (42\%) with abnormal sensation at least once during the oneyear follow up. These 87 patients were grouped based on the 


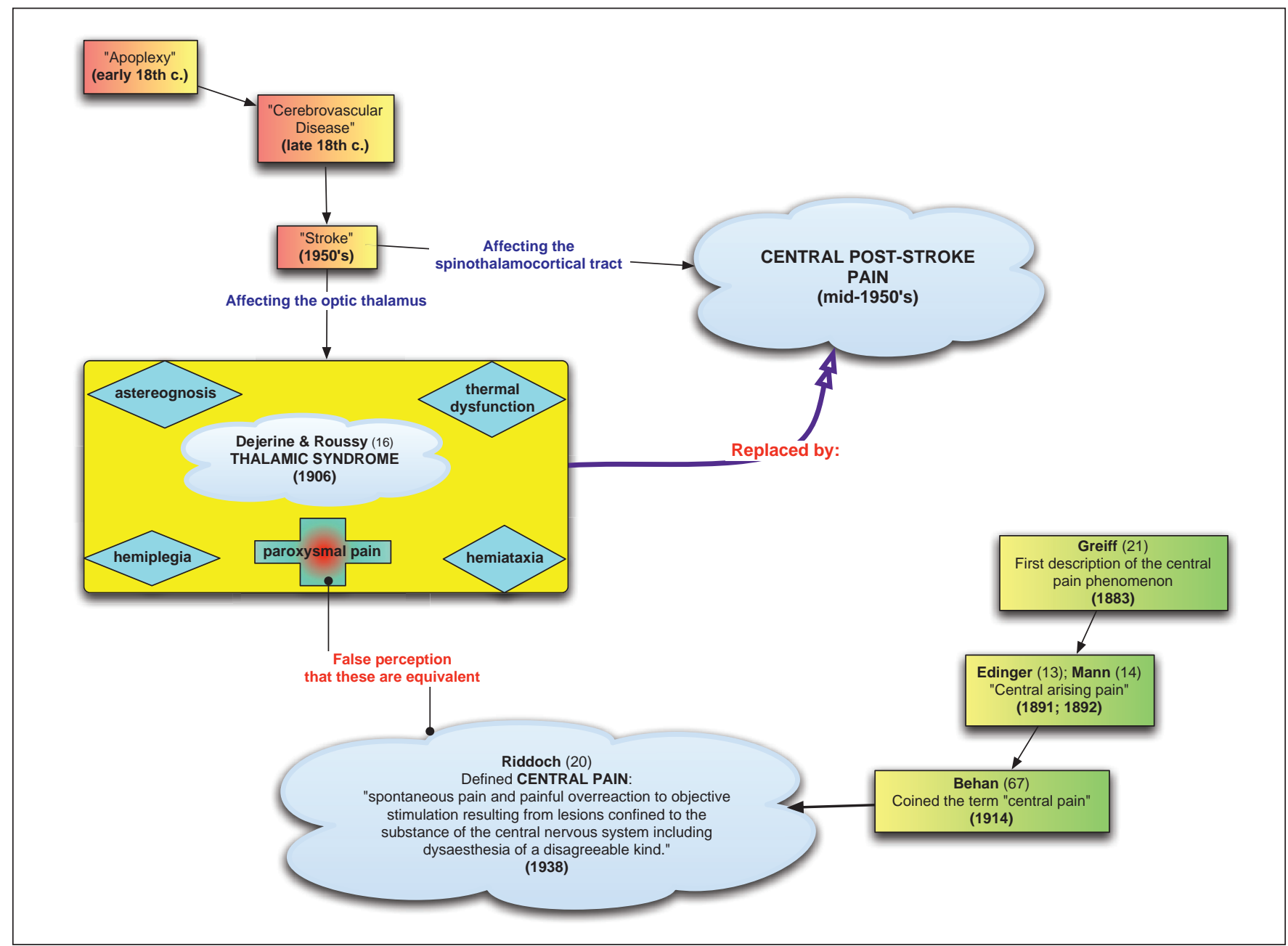

Figure 1) The relationships between 'stroke', 'central pain', 'thalamic syndrome' and 'central poststroke pain'

presence $(\mathrm{CPSP}=16)$ or absence $($ nonpain $=71)$ of pain, and compared in terms of numerous modalities. The CPSP group displayed “...significantly more abnormal sensibility to cold and warm stimuli than the non-pain patients with somatosensory dysfunction". Abnormal thermal sensation is a well-documented feature of CPSP and these results correspond well with the notion that spinothalamic dysfunction is intrinsic to this disorder. Anderson et al (24) also noted the presence of touch allodynia (pain evoked by a stimulus that is normally nonpainful) and dysesthesia exclusively in the CPSP group. Lastly, the levels of abnormal pinprick sensibility were found to be similar between the CPSP and nonpain groups, implying that pinprick and thermal stimuli follow different patterns of pathology in patients with somatosensory dysfunction (24).

Further discussion of sensory abnormalities in 11 of the original 16 CPSP patients is presented in a companion paper published by Vestergaard et al (27). Temperature stimuli between $10^{\circ} \mathrm{C}$ and $45^{\circ} \mathrm{C}$ were used to evaluate evoked sensations in nine of the 11 CPSP patients (27). These responses were found to be abnormal in seven $(78 \%)$ of the nine subjects, and ranged from distorted cold or heat sensations to clear paradoxical reactions to the various stimuli. It is interesting to note that $88 \%$ of the original 16 CPSP subjects exhibited allodynia or dysesthesia to cold, compared with only $3 \%$ of those patients with somatosensory deficits but without pain. Allodynia or dysesthesia evoked by touch was observed in $75 \%$ of the CPSP subjects, but was present in none of the pain-free patients (24). As well, the pain in all 16 CPSP patients was confined within the regions of altered pinprick sensation, with the painful areas either equal to or falling short of the borders of sensory dysfunction. The authors noted that similar phenomena have been observed in phantom limb pain, peripheral nerve lesions and spinal cord injury, suggesting that common mechanisms for sensory disturbance exist between CPSP and other neuropathic disorders $(24,27)$.

Greenspan et al (28) also evaluated somatosensory abnormalities in a group of CPSP patients $(n=13)$. A validated questionnaire was used to describe the nature of pain, and various psychophysical tests were employed to measure thresholds for innocuous warm and cold, painful heat and cold, and innocuous tactile sensations on the dorsum of the hands or feet. Additionally, evoked allodynia was measured in response to cutaneous brush stimuli. These authors reported that cold hypoesthesia, often associated with a burning, cold, ongoing pain, was associated with the absence of cold allodynia. As well, “...tactile hypoesthesia was significantly associated with the absence of tactile allodynia while normal tactile sensibility was associated with the presence of tactile allodynia”.

In summary, CPSP is characterized by significant abnormalities in temperature and pain sensitivity as well as the sensory 
disturbances of allodynia and dysesthesia. Other characteristic features of this condition include a poor localization of stimuli and disassociation between thermal pathways and pinprick sensation.

\section{LOCUS AND PATHOPHYSIOLOGY}

CPSP appears to be associated with stroke-induced lesions in the spinothalamic tract, irrespective of stroke type or demographics $(10,24,27)$. Although early research identified the thalamus as the source of CPSP (16), more recent research has demonstrated that this type of pain has a much more complex pathophysiology. Thus, while the thalamus is still recognized as a key pathophysiological component, radiological techniques have shown lesions which have led to CPSP may be located at any level along the neuraxis, and furthermore that the macrostructure of the lesion is probably less important than its location (10). The fact that essentially all patients with CPSP have deficits of temperature and pain sensibility suggests that lesions of the spinothalamic pathway are involved (29). These somatosensory deficits, along with the central NeP, are unifying characteristics in these patients. It is important to understand that CPSP is a somatosensory phenomenon, and although an injury may affect tracts involved in motor function, this is strictly a consequence of the anatomical proximity of the motor tracts to the sensory tracts.

With limited evidence of possible mechanisms, and thus limited rationale to direct drug development, one may turn to clues regarding the pathophysiology of CPSP. For example, most CPSP patients present within one or two months of stroke, but some develop this pain one to six years post stroke $(24,27)$. In addition to creating a source of diagnostic uncertainty and significant delay in treatment, this latency period must also be factored into any hypothesis relating to the mechanisms of this disease.

Another possible mechanistic clue lies in the localization of lesions that give rise to CPSP. Alterations in thalamocortical processing can occur after thalamic lesions, including loss of inhibition or sensitization (30). A potential mechanism is subthreshold activation of nociceptive neurons, in which nociceptive neurons discharge in response to a normally nonpainful stimulus. As indicated above, damage to the spinothalamic tract is generally accepted as a necessary locus for development of CPSP. Thus, vascular occlusion or hemorrhage at any level of the neuraxis may lead to damage of this tract. Most commonly, lesions within the ventrocaudal nuclei of the thalamus, particularly within the ventroposterior inferior nucleus, are associated with CPSP $(31,32)$. Nociceptive and thermosensitive neurons within the ventromedial thalamus, when stimulated, produce specific pain responses (33). Cutaneous nociceptive input is encoded and conducted via specific neurons in the ventromedial thalamus. Thus, while there is presently no consensus regarding the pathogenesis of CPSP, various theories have been put forward, including hyperexcitability of thalamic neurons after interruption of ascending fibres in the spinothalamic pathway (34), release of inhibition through a specific lesion to the lemniscal pathway or the spinothalamic tract $(10,35)$, and release of inhibition through degeneration of corticothalamic neurons that project to the reticular nucleus and activate gamma-aminobutyric acid-ergic inhibitory neurons which regulate neuronal excitability in the somatosensory relay nuclei of the thalamus $(36,37)$.
It has been reported that CPSP may develop as a complication of Wallenberg's syndrome, also known as lateral medullary infarction. This neurological disorder is caused by a stroke in the vertebral or posterior inferior cerebellar arteries of the brain stem. Due in part to the fact that the spinothalamic tract is within the lateral medulla, Wallenberg infarcts are associated with significant risk of central pain. In 1997, MacGowan et al (38) sought to determine the frequency of central pain in a cohort $(n=63)$ of lateral medullary infarction patients. These researchers defined the pain as a "chronic, spontaneous irritating sensation, often aggravated by both innocuous and noxious stimuli, and not explained by any peripheral nociceptive cause". Outcome measures included clinical sensory examination (ie, responses to pinprick, cold tuning fork), magnetic resonance imaging data and quantitative sensory testing. It is important to note that quantitative sensory testing was performed in only 19 of the 63 patients. Central pain was reported in $16(25 \%)$ of the lateral medullary infarction patients within six months, which is significantly higher than all previously reported incidence rates. The authors of this study suggested that this amplified incidence was due to the highly specific lesions involved in Wallenberg's syndrome. This specificity has clinical resemblance to lesions of the ventroposterolateral thalamic nucleus, which have been associated with a central pain complication rate of $17 \%$ (39). These studies demonstrate that CPSP incidence may be heightened in populations where highly selective spinothalamic or thalamocortical injury is observed.

A third possible clue to the overall mechanisms of CPSP is the loss of thermal sensation that accompanies, and often precedes, the onset of pain (24). This observation may point to a more global etiology of the pain, such as a general loss of inhibitory mechanisms in the sensory thalamus, or in pathways projecting into the thalamus. Consistent with this concept are the reduced numbers of opiate receptors in the thalamus and cortex reported in various imaging studies (40-42). It is not known, however, whether this decreased binding is due to increased release of endogenous opioids, receptor internalization, downregulation of receptor biosynthesis or loss of neurons carrying these receptors.

Overall, these data are difficult to reconcile with a simple mechanistic explanation, such as disinhibition. Instead, they would be consistent with the notion of a multifactorial basis for CPSP, such as dysfunction in a network of interrelated neurons.

\section{STROKE TO PAIN LATENCY: INCIDENCE AND TIME TO ONSET}

Adding to the difficulty in deriving incidence is the remarkable delay between the occurrence of stroke and the development of CPSP that has been observed in some patients. In a study involving 27 CPSP subjects, Leijon et al (29) reported 13 patients (48\%) with time to onset of CPSP between one and 34 months. They also noted that 20 patients (74\%) experienced gradually increasing pain rather than a sudden onset. In a later study, Anderson et al (24) followed 267 stroke patients for up to 12 months to estimate CPSP incidence. Of the 191 patients remaining in the study after one year, 16 (8.4\%) eventually developed CPSP. Approximately $38 \%$ of these 16 patients displayed latency periods of between one and 12 months, which roughly corresponds to the findings of Leijon et al. In a companion paper to Anderson et al (24), 
Vestergaard et al (27) more thoroughly described the condition of these CPSP patients. However, this study included only 11 of the original 16 subjects and the data provided concerning time to onset did not correspond with the data of Anderson et al (24).

A clearer description is provided by a study involving stroke $(n=111)$ and subarachnoid hemorrhage $(n=19)$ patients who experienced central pain (43). Pain onset was immediate in a minority of patients, while latency periods in the remaining patients ranged from a few weeks to six years. Overall, 63 (57\%) stroke patients and $16(84 \%)$ subarachnoid hemorrhage patients experienced pain latency to some degree.

These studies strongly suggest that significant delays between stroke occurrence and onset of CPSP exist, and must be taken into account. Bowsher (43) and others have noted that this delay to onset contributes to misdiagnosis, as well as delays in commencement of treatment, because the patient may no longer be under close neurological observation when central pain develops. A further methodological complication in many existing studies is the potential for bias among CPSP patients asked to recollect when their pain began. A more appropriate approach would be to design a large, prospective study involving consecutive acute stroke patients. This design would promote reliable monitoring of CPSP incidence and enable reliable documentation of time to onset.

\section{EPIDEMIOLOGY OF CPSP}

The ideal method of determining disease incidence is to prospectively follow a large cohort of comparable subjects for a significant period of time and monitor when and how disease develops (44). The most commonly cited study of CPSP incidence did indeed follow a sizable population of stroke patients $(n=267)$ for a period of one year (24). These patients were examined during the first week of admission and at one, six and 12 months after stroke. Outcome measures included computed tomography (CT) scans, psychological assessment and clinical testing of modalities such as responses to touch, temperature and pinprick. Although there have been no universal characteristic signs reported among CPSP patients, the presence of abnormal thermal sensation is almost invariably present (45). In this study, CPSP was demonstrated in 16 (8.4\%) of the 191 patients remaining after one year.

Taking into account the observation of Bowsher (43) that the time to onset of CPSP may extend up to six years post stroke, $8.4 \%$ should be interpreted as a minimum rather than an approximate estimation of incidence.

In the study of Anderson et al (24), there were no significant differences in terms of age, sex, stroke history or physical outcome between the 16 CPSP patients and the 71 patients with somatosensory deficits but without pain. Considering the CT scans of all patients with somatosensory deficits, CPSP patients were found to have significantly more acute stroke lesions and larger lesions. Examining only patients with single acute lesions on CT scans and somatosensory deficits, there was no significant difference in size or distribution of lesions between CPSP patients $(n=11)$ and patients with sensory deficits but without pain $(n=20)$. Overall, the authors concluded that "...the lesions giving rise to CPSP can be rightsided and left-sided, thalamic and extrathalamic, supra- as well as infratentorial. The significance of CT lesions and pain is difficult to determine as many patients have more than one lesion".
In terms of the natural history of CPSP, our search of the literature did not reveal any reference to the reversal or waning of symptoms over time. There is certainly a great opportunity at present for examining the epidemiology of CPSP in greater depth, in a large number of stroke patients, followed for more than one year.

\section{AGE AND INCIDENCE}

The purported age difference between poststroke patients who develop CPSP and those who do not is a subject of some debate in the literature (35). In a descriptive study involving 27 CPSP subjects, Leijon et al (29) reported a relatively young age of stroke onset (mean age 62 years), compared with the general stroke population (mean age 72 years). Anderson et al (24), however, found no disparity in age between the patients that go on to develop CPSP $(n=87)$ versus those that do not $(n=120)$. Furthermore, among those subjects with somatosensory deficits, there was no age difference between the 16 who developed pain and the remainder who did not. In a subsequent study, Bowsher (43) found a significant difference in age of stroke onset between 130 CPSP patients (median age 57 years) and the whole stroke population (median age 75 years). The method of recruitment for this study may have been subject to selection bias, however, as all patients were referred to Bowsher. Because the subjects are passing through a referral filter before entering the study, they may not represent the underlying CPSP population. Similarly, a fairly recent publication from Sweden $(n=15)$ reporting a median age of 65 years at the time of stroke onset may be unrepresentative of the general population due to exclusion of patients with intellectual or communication difficulties and without knowledge of Swedish (46).

In view of this divergence of reports, it is suggested that the collection and inclusion of CPSP data within existing stroke registries may facilitate more concrete comparisons of age of onset between poststroke populations with and without central pain.

\section{TREATMENT}

Our incomplete understanding of the mechanisms underlying CPSP challenges the development of targeted treatment strategies (35). Moreover, the dearth of published data from large, well-designed clinical trials involving patients with CPSP has created a situation where guidelines for treatment are based upon "uncontrolled studies, clinical experience and expert opinion” (47).

Evaluated therapies have been largely unsuccessful in controlling symptoms, particularly oral drug therapies $(48,49)$. It is not the intent of the present review to provide details on oral drug therapies; interested readers are encouraged to refer to the sources cited. Amitriptyline, a tricyclic antidepressant, is usually the drug of first choice $(26,50,51)$. However, its utility is limited by common adverse effects such as dry mouth, drowsiness and constipation, as well as more rare instances of urinary retention, orthostatic hypotension and cardiac arrhythmia (35). It is tempting to speculate that the apparent analgesic effect of amitriptyline may in fact stem from its mood-enhancing properties; however, such analgesia is not necessarily accompanied by a reduction in depressive symptoms (26). In fact, amitriptyline has been shown to be clinically effective in the treatment of peripheral $\mathrm{NeP}$ in nondepressed patients $(26,52)$. Furthermore, the dose and 
blood levels of amitriptyline associated with pain relief are in the lower range of doses required for resolution of depression (53). Considering this evidence, the linear relationship between amitriptyline, mood elevation and pain reduction must be reassessed. An association wherein amitriptyline operates to relieve symptoms of depression and pain via independent mechanisms has become increasingly persuasive in recent years $(53,54)$.

Gordon (47) aptly summarizes the current state of pharmacotherapy for the treatment of CPSP. Nonsteroidal antiinflammatory drugs such as ibuprofen, acetylsalicylic acid and cyclo-oxygenase-2 inhibitors are not recommended. Antidepressants $(26,51,52)$ such as amitriptyline and nortriptyline, as well as antiepileptics including lamotrigine, gabapentin, pregabalin and carbamazepine can be used as first-line treatments. For patients refractory to these treatments, opioids such as morphine (55) or levorphanol (56) may be prescribed, although no large studies have directly examined their efficacy for CPSP. Local anesthetics such as lidocaine $(55,57), \mathrm{N}$-methyl-D-aspartate receptor antagonists including ketamine (58), cannabinoids, and botulinum toxin $\mathrm{A}$ are not recommended. In terms of combination therapy, gabapentin or pregabalin with amitriptyline is not effective. For an in-depth review of pharmacological treatments for chronic neuropathic pain in general and CPSP in particular, please refer to 59 and 57 , respectively.

Nonpharmacological interventions have also been used in the treatment of CPSP. For example, deep brain stimulation of the central grey matter was used years ago for intractable pain. Nandi and Aziz (60) recently reported beneficial effects of deep brain stimulation in 13 of 19 patients with central pain, although it was not clear how many suffered from multiple sclerosis or spinal injury versus CPSP. Due to the immense skill and considerable hospital resources needed for brain stimulation, this is a very rarely exercised treatment option (48).

Tsubokawa et al (61) report that chronic epidural electrical stimulation of the motor cortex results in a reduction in pain. Subsequent results of motor cortex stimulation to alleviate pain in patients with CPSP have variable and less than satisfactory results, considering the invasiveness of the intervention (62). For example, Katayama et al (63) report some degree of pain control in $50 \%$ of patients using motor cortex stimulation. Nguyen et al (64) report a 77\% success rate, although on speaking with one of the authors personally, the actual results are considerably less encouraging. Further refinements are being made to motor cortex stimulation (65) and, considering that the success rate remains suboptimal and quite variable from one clinic to another, this approach to treatment of CPSP is far from satisfactory.

On a more positive note, the use of tPA for selected stroke patients significantly curtails the morbidity and mortality associated with acute ischemic stroke (9). By salvaging the ischemic penumbra, tPA may also prevent damage to the spinothalamocortical tract, and thus reduce the subsequent risk of CPSP (66). Due to its highly specific treatment criteria, however, tPA is currently unavailable to the majority of stroke patients (9). Among other improvements, efforts to extend the treatment window of tPA beyond three hours will surely contribute to the prophylaxis of CPSP.

It is important to remember that the CPSP patient is likely to experience not only pain and sensory abnormalities, but also considerable emotional distress. Behavioural therapies, massage, physical therapy and acupuncture are therefore recommended for alleviation of the anxiety, depression and sleep disorders that often accompany chronic pain syndromes such as CPSP (48).

\section{CONCLUSIONS}

CPSP is a common, but underappreciated, consequence of stroke. The estimated incidence of $8 \%$ is misleading, considering the enormous burden of stroke in the population. CPSP is characterized by constant or intermittent pain and associated with sensory abnormalities, particularly of thermal sensation. It is one manifestation of central pain, a notoriously mysterious neurological ailment. A significant proportion of stroke patients experience a latency period before the onset of CPSP symptoms. Also adding to the diagnostic challenge of this disease are the similarities with other disorders such as frozen shoulder syndrome, complex regional pain syndrome and musculoskeletal problems. There is no clear relationship between patient age and risk of CPSP development.

The relatively large number of different drug classes that have reported some efficacy in the treatment of CPSP suggests that a plethora of mechanisms may be contributing to this disease. The apparent lack of universal effectiveness of any drug class and the ineffectiveness of all therapeutic approaches in the vast majority of patients are also suggestive of multiple mechanisms. Further, neuronal damage resulting from a stroke is suggestive of the involvement of local neurotoxicity, often attributed to glutamate. The reported efficacy of antidepressants in reducing CPSP in some patients implicates multiple chemical mechanisms. Effectiveness of anticonvulsants and antiarrhythmics implicate calcium and sodium channels. Opioids implicate opioid receptors. This evidence is all consistent with the possibility of a complex etiology and maintenance of CPSP. Is there a single point of commonality of most or all of these possible mechanisms? Future research must aim to find out.

\section{REFERENCES}

1. Schott GD. From thalamic syndrome to central poststroke pain. J Neurol Neurosurg Psychiatry 1996;61:560-4.

2. Thom T, Haase N, Rosamond W, et al. Heart disease and stroke statistics - 2006 update: A report from the American Heart Association Statistics Committee and Stroke Statistics Subcommittee. Circulation 2006;113:e85-151.

3. Tasker R. Central pain states. In: Loeser JD, ed. Bonica's Management of Pain, $3^{\text {rd }}$ edn. Philadelphia: Lippincott Williams \& Wilkins, 2001:432-53.

4. Henry J, Yashpal K, Lalloo C. Central poststroke pain: A perspective. In: Henry J, Panju A and Yashpal K, eds. Central Neuropathic Pain: Focus on Poststroke Pain. Seattle: IASP Press, 2007:3-5.

5. Warlow C, Dennis M, van Gijn J, et al. Stroke: A Practical Guide to Management, $2^{\text {nd }}$ edn. Oxford: Blackwell Science, 2001.

6. Pound P, Bury M, Ebrahim S. From apoplexy to stroke. Age Ageing 1997;26:331-7.

7. Fatahzadeh M, Glick M. Stroke: Epidemiology, classification, risk factors, complications, diagnosis, prevention, and medical and dental management. Oral Surg Oral Med Oral Pathol Oral Radiol Endod 2006; 102:180-91.

8. Powers W, Raichle M. Stroke. In: Pearlman A, Collins RC, eds. Neurological Pathophysiology, 3rd edn. New York: Oxford University Press, 1984:287-302.

9. Tissue plasminogen activator for acute ischemic stroke. The National Institute of Neurological Disorders and Stroke rt-PA Stroke Study Group. N Engl J Med 1995;333:1581-7. 
10. Boivie J, Leijon G, Johansson I. Central post-stroke pain - a study of the mechanisms through analyses of the sensory abnormalities. Pain 1989;37:173-85.

11. Déjerine J, Egger J. Contribution à l'étude de la physiologie pathologique de l'incoordination motrice. Rev Neurol 1903;11:397-405.

12. Langworthy OR, Fox HM. Thalamic syndrome: Syndrome of the posterior cerebral artery: A review. Arch Intern Med 1937;60:203-24

13. Edinger L. Giebt es central entstehende Schmerzen? Dtsch Z Nervenheilkd 1891;1:262-82.

14. Mann L. Casuistischer Beitrage zur Lehre vom central entstehenden Schmerze. Berl Klin Wochenschr 1892;29:244-5.

15. Mitchell SW. Clinical Lessons on Nervous Diseases. Philadelphia: Lea Brothers, 1897.

16. Déjerine J, Roussy G. Le syndrome thalamique. Rev Neurol 1906;14:521-32.

17. Wilkins RH, Brody IA. The thalamic syndrome. Arch Neurol 1969;20:559-62.

18. Head H. Studies in Neurology. London: Hodder \& Stoughton, 1920.

19. Scadding JW. Treatment of neuropathic pain: Historical aspects. Pain Med 2004;5(Suppl 1):S3-8.

20. Riddoch $G$. The clinical features of central pain. Lancet 1938;234:1093-8.

21. Greiff F. Zur localization der Hemichorea. Arch Psychol Nervenkr 1883;14:598-624.

22. Cassinari V, Pagni CA. Central pain. A neurosurgical survey. Cambridge: Harvard University Press, 1969.

23. Nashold B, Ovelmen-Levitt J. History of thalamic syndrome. In: Nashold B, Ovelmen-Levitt J, eds. Advances in Pain Research and Therapy. Deafferentation Pain Syndromes: Pathophysiology and Treatment. New York: Raven Press, 1991:1-367

24. Andersen G, Vestergaard K, Ingeman-Nielsen M, Jensen TS. Incidence of central post-stroke pain. Pain 1995;61:187-93.

25. Segatore M. Understanding central post-stroke pain. J Neurosci Nurs 1996;28:28-35.

26. Bowsher D. Central post-stroke ('thalamic syndrome') and other central pains. Am J Hosp Palliat Care 1999;16:593-7.

27. Vestergaard K, Nielsen J, Andersen G, Ingeman-Nielsen M, Arendt-Nielsen L, Jensen TS. Sensory abnormalities in consecutive, unselected patients with central post-stroke pain. Pain 1995;61:177-86.

28. Greenspan JD, Ohara S, Sarlani E, Lenz FA. Allodynia in patients with post-stroke central pain (CPSP) studied by statistical quantitative sensory testing within individuals. Pain 2004;109:357-66.

29. Leijon G, Boivie J, Johansson I. Central post-stroke pain neurological symptoms and pain characteristics. Pain 1989;36:13-25.

30. Dostrovsky JO, Manduch M, Davis KD, Tasker RR, Lozano AM. Thalamic stimulation-evoked pain and temperature sites in pain and non-pain patients. In: Devor M, Rowbotham MC, Wiesenfeld-Hallen Z, eds. Proceedings, World Congress on Pain. Seattle: IASP Press, 2000:419-25.

31. Bowsher D. Allodynia in relation to lesion site in central poststroke pain. J Pain 2005;6:736-40.

32. Kim JH, Greenspan JD, Coghill RC, Ohara S, Lenz FA. Lesions limited to the human thalamic principal somatosensory nucleus (ventral caudal) are associated with loss of cold sensations and central pain. J Neurosci 2007;27:4995-5004.

33. Davis KD, Kiss ZH, Luo L, Tasker RR, Lozano AM, Dostrovsky JO. Phantom sensations generated by thalamic microstimulation. Nature 1998;391:385-7.

34. Koyama S, Katayama Y, Maejima S, Hirayama T, Fujii M, Tsubokawa T. Thalamic neuronal hyperactivity following transection of the spinothalamic tract in the cat: Involvement of $\mathrm{N}$-methyl-D-aspartate receptor. Brain Res 1993;612:345-50.

35. Hansson P. Post-stroke pain case study: Clinical characteristics, therapeutic options and long-term follow-up. Eur J Neurol 2004;11(Suppl 1):22-30.

36. Maruno N, Kaminaga T, Mikami M, Furui S. Activation of supplementary motor area during imaginary movement of phantom toes. Neurorehabil Neural Repair 2000;14:345-9.

37. Roux FE, Ibarrola D, Lazorthes Y, Berry I. Chronic motor cortex stimulation for phantom limb pain: A functional magnetic resonance imaging study: Technical case report. Neurosurgery 2001;48:681-7. (Discussion in 2001;48:687-8).

38. MacGowan DJ, Janal MN, Clark WC, et al. Central poststroke pain and Wallenberg's lateral medullary infarction: Frequency, character, and determinants in 63 patients. Neurology 1997;49:120-5.

39. Bogousslavsky J, Regli F, Uske A. Thalamic infarcts: Clinical syndromes, etiology, and prognosis. Neurology 1988;38:837-48.

40. Willoch F, Schindler F, Wester HJ, et al. Central poststroke pain and reduced opioid receptor binding within pain processing circuitries: A [11C]diprenorphine PET study. Pain 2004;108:213-20.

41. Jones AK, Watabe H, Cunningham VJ, Jones T. Cerebral decreases in opioid receptor binding in patients with central neuropathic pain measured by [11C]diprenorphine binding and PET. Eur J Pain 2004;8:479-85.

42. Sprenger T, Berthele A, Platzer S, Boecker H, Tölle TR. What to learn from in vivo opioidergic brain imaging? Eur J Pain 2005;9:117-21.

43. Bowsher D. Central pain: Clinical and physiological characteristics. J Neurol Neurosurg Psychiatry 1996;61:62-9.

44. Gordis L. Epidemiology, $3^{\text {rd }}$ edn. Philadelphia: Saunders, 2004.

45. Boivie J. Central Pain. In: Merskey H, Loeser J, Dubner R, eds. The Paths of Pain 1975-2005. Seattle: IASP Press, 2005:299. 312.

46. Widar M, Samuelsson L, Karlsson-Tivenius S, Ahlström G. Long-term pain conditions after a stroke. J Rehabil Med 2002;34:165-70.

47. Gordon A. Best practice guidelines for treatment of central pain after stroke. In: Henry JL, Panju A, Yashpal K, eds. Central Neuropathic Pain: Focus on Poststroke Pain. Seattle: IASP Press, 2007.

48. Backonja MM, Serra J. Pharmacologic management part 2: Lesser-studied neuropathic pain diseases. Pain Med 2004;5(Suppl 1):S49-59.

49. Nicholson BD. Evaluation and treatment of central pain syndromes. Neurology 2004;62(Suppl 2):S30-6.

50. Leijon G, Boivie J. Central post-stroke pain - a controlled trial of amitriptyline and carbamazepine. Pain 1989;36:27-36.

51. Lampl C, Yazdi K, Röper C. Amitriptyline in the prophylaxis of central poststroke pain. Preliminary results of 39 patients in a placebo-controlled, long-term study. Stroke 2002;33:3030-2.

52. McQuay HJ, Tramèr M, Nye BA, Carroll D, Wiffen PJ, Moore RA. A systematic review of antidepressants in neuropathic pain. Pain 1996;68:217-27.

53. McQuay HJ, Carroll D, Glynn CJ. Dose-response for analgesic effect of amitriptyline in chronic pain. Anaesthesia 1993;48:281-5.

54. Jasmin L, Tien D, Janni G, Ohara PT. Is noradrenaline a significant factor in the analgesic effect of antidepressants? Pain 2003;106:3-8.

55. Attal N, Guirimand F, Brasseur L, Gaude V, Chauvin M, Bouhassira D. Effects of IV morphine in central pain: A randomized placebo-controlled study. Neurology 2000;58:554-63.

56. Rowbotham MC, Twilling L, Davies PS, Reisner L, Taylor K, Mohr D. Oral opioid therapy for chronic peripheral and central neuropathic pain. N Engl J Med 2003;348:1223-32.

57. Frese A, Husstedt IW, Ringelstein EB, Evers S. Pharmacologic treatment of central post-stroke pain. Clin J Pain 2006;22:252-60.

58. Vick PG, Lamer TJ. Treatment of central post-stroke pain with oral ketamine. Pain 2001;92:311-3.

59. Moulin DE, Clark AJ, Gilron I, et al. Pharmacological management of chronic neuropathic pain - consensus statement and guidelines from the Canadian Pain Society. Pain Res Manag 2007;12:13-21. 
60. Nandi D, Aziz TZ. Deep brain stimulation in the management of neuropathic pain and multiple sclerosis tremor. J Clin Neurophysiol 2004;21:31-9.

61. Tsubokawa T, Katayama Y, Yamamoto T, Hirayama T, Koyama S. Chronic motor cortex stimulation for the treatment of central pain. Acta Neurochir Suppl (Wien) 1991;52:137-9.

62. Hosobuchi Y. Motor cortical stimulation for control of central deafferentation pain. Adv Neurol 1993;63:215-7.

63. Katayama Y, Fukaya C, Yamamoto T. Poststroke pain control by chronic motor cortex stimulation: Neurological characteristics predicting a favorable response. J Neurosurg 1998;89:585-91.

64. Nguyen JP, Lefaucheur JP, Decq P, et al. Chronic motor cortex stimulation in the treatment of central and neuropathic pain. Correlations between clinical, electrophysiological and anatomical data. Pain 1999;82:245-51.

65. Pirotte B, Voordecker P, Neugroschl C, et al. Combination of functional magnetic resonance imaging-guided neuronavigation and intraoperative cortical brain mapping improves targeting of motor cortex stimulation in neuropathic pain. Neurosurgery 2005;56(Suppl 2):344-59.

66. Gladstone D, Black S. Overview of current and emerging therapies for acute stroke. In: Henry JL, Panju A, Yashpal K, eds. Central Neuropathic Pain: Focus on Poststroke Pain. Seattle: IASP Press, 2007:13-25. 


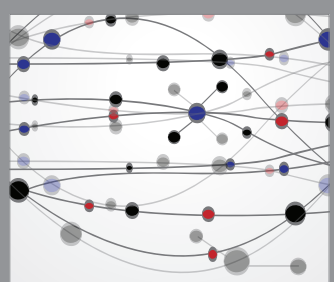

The Scientific World Journal
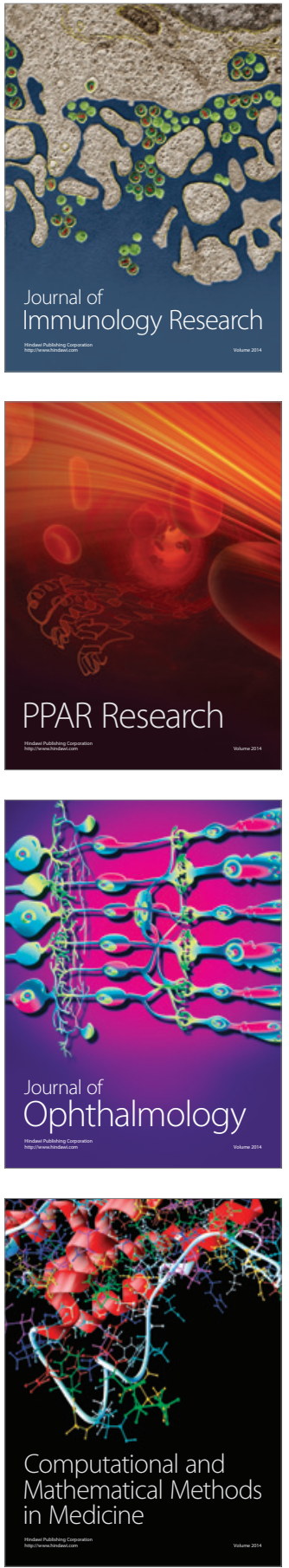

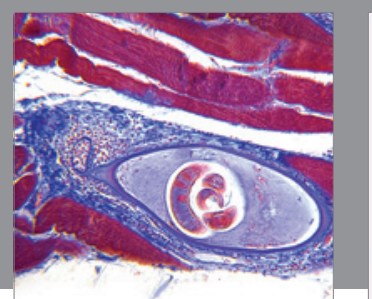

Gastroenterology Research and Practice

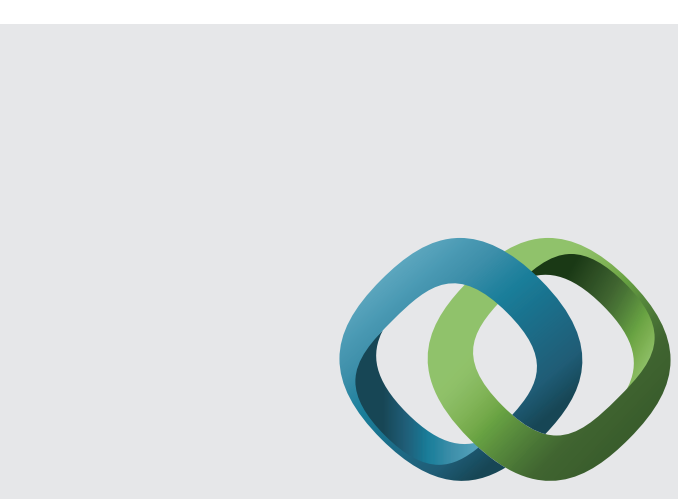

\section{Hindawi}

Submit your manuscripts at

http://www.hindawi.com
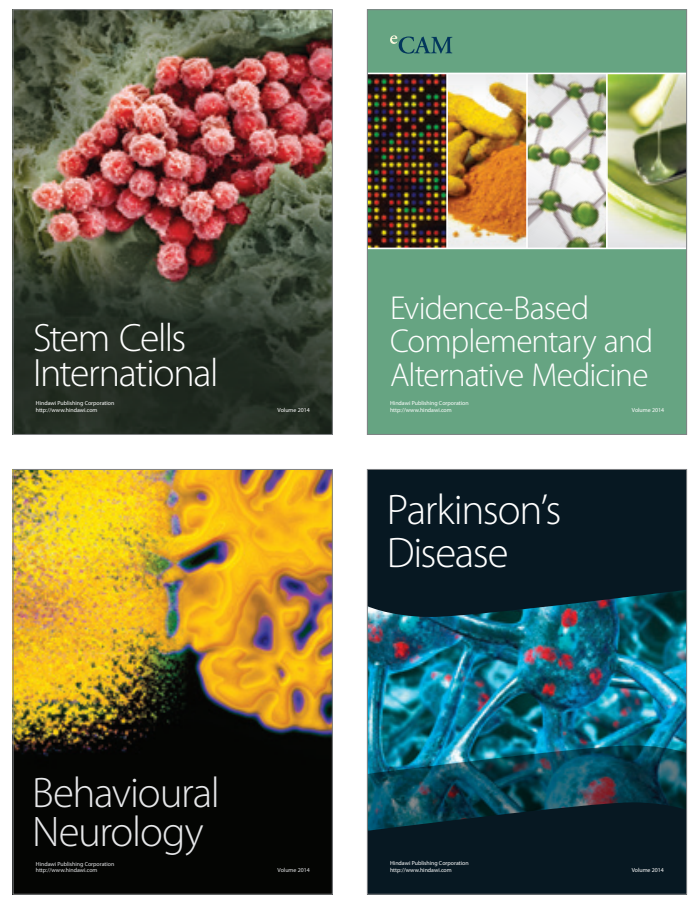
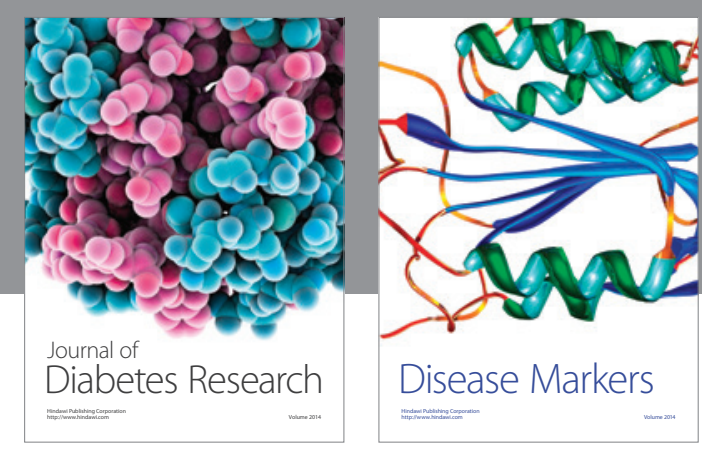

Disease Markers
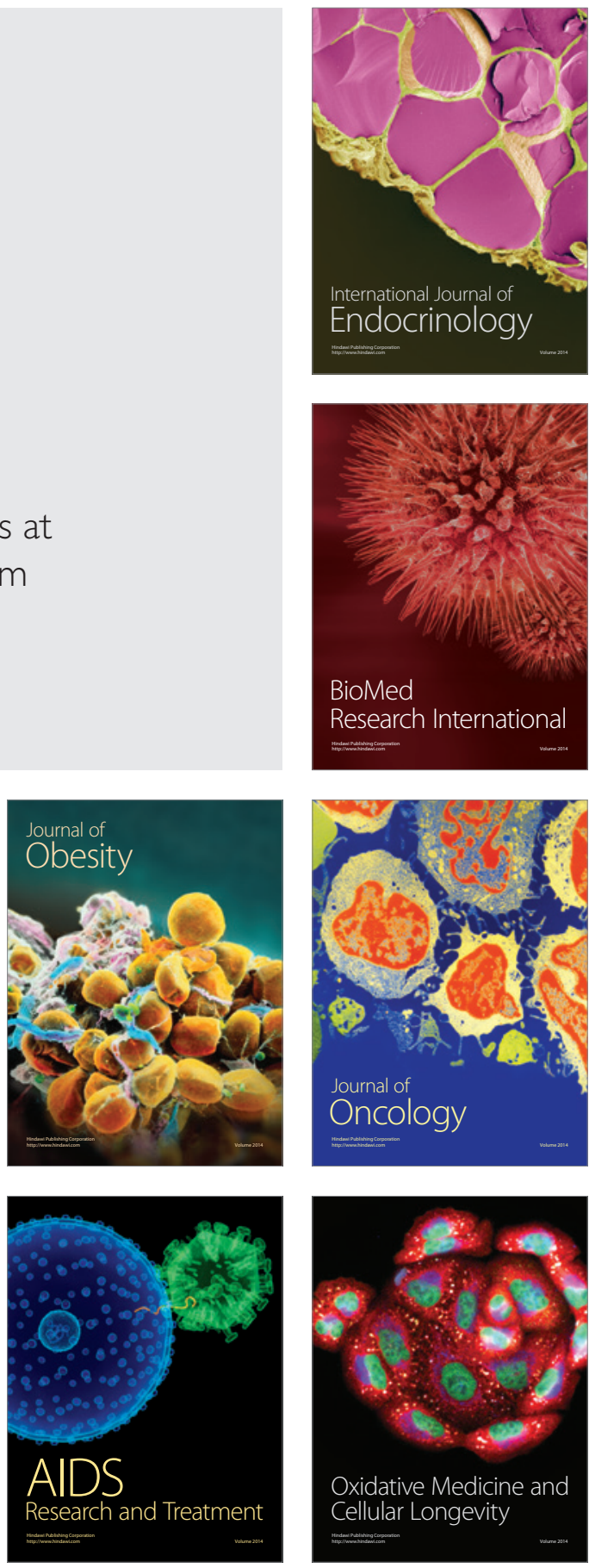